excluded; and (3) the patients were breast fed by their mothers although the mothers died many years ago and no serological tests had been performed.

The familial clustering has been reported in a number of autoimmune diseases in which the genetic predisposition plays a role in the disease susceptibility. The present case with familial occurrence of HTLV-I uveitis may suggest an involvement of infectious/autoimmune overlap in the pathogenesis of the disease. The transmission of HTLV-I carrier state and the presence of HTLV-I infected cells in the eye are essential for the development of the disease. However, clinical disease was apparent in only a few of the seropositive family member. The presence of disease only in certain HTLV-I infected family members, therefore, suggests that host factors also play a role in the disease development. It has been reported that immunogenetic factors in the host determine susceptibility to HAM/TSP." Therefore, the survey of immunogenetic factors in HTLV-I uveitis may provide us with further information to understand the pathogenesis of the disease and this is now in progress.

1 Blattner WA. Epidemiology of HTLV-I and associated diseases. In: Blattner WA, ed. Human retrovirology. HTLV. New York: Raven Press, 1990: 251-65.
2 Yoshida M, Seiki M, Yamaguchi K, Takatsuki K. Monoclonal integration of human T-cell leukemia suggests causative role of human T-cell leukemia virus in the disease. Proc Nat Acad Sci USA 1984; 81: 2534-7.

3 Gessain A, Barin F, Vernant JC, Gou O, Calender A, de-The G. Antibody to the human T-lymphotropic virus type-I in patients with tropical spastic paraparesis. Lancet 1985; ii: 407-10.

4 Mochizuki M, Yamaguchi K, Takatsuki K, Watanabe T, Mori S, Tajima K. HTLV-I and uveitis. Lancet 1992; 339. 1110 .

5 Mochizuki M, Watanabe T, Yamaguchi K, Yoshimura K, Nakashima S, Shirao $M$, et al. Uveitis associated with human T-cell lymphotropic virus type I. Am ₹ Ophthalmol 1992; T-cell lymp

6 Mochizuki $M$, Watanabe $T$, Yamaguchi $K$, Takatsuki $K$ Yoshimura K, Shirao M, et al. HTLV-I uveitis: a distinct clinical entity caused by HTLV-I. fpn $\mathcal{f}$ Cancer Res 1992 83: 236-9.

7 Yoshimura K, Mochizuki M, Araki S, Miyata N, Yamaguchi $\mathrm{K}$, Tajima $\mathrm{K}$, et al. Analysis of clinical and immunological features of human T-cell lymphotropic virus type I uveitis. Am $\mathcal{F}$ Ophthalmol 1993 (in press).

8 Yamaguchi K, Yul LS, Shimizu T, Nozawa F, Takeya $M$, Takahashi K, et al. Concurrence of lymphoma type adult

9 Salazar-Grueso EF, Holzer TJ, Gutierrez RA, Casey JM, Desai SM, Devare SG, et al. Familial spastic paraparesis syndrome associated with HTLV-I infection. $N$ Englf Med 1990; 323: 732-7.

10 Miyoshi I, Taguchi H, Fujishima M, Niiya K, Kitagawa T, Ohtsuki Y, et al. Asymptomatic type $\mathrm{C}$ virus carriers in the family of an adult T-cell leukemia patient. Gann 1982; 73: 339-40.

11 Sonoda S. Genetic and immunologic determinants of HTLVI-associated diseases. In: Blattner W, ed. Human retrovirology: HTLV. New York: Raven Press, 1990: $315-26$

\title{
An atypical Leber's hereditary optic neuropathy with the 11778 mutation
} Yoshihiro Hotta, Mutsuko Hayakawa, Keiko Fujiki, Koutaro Shinohara, Kazushige Sado,
Atsushi Kanai, Kenji Yanashima

Leber's hereditary optic neuropathy (LHON) is a maternally inherited disease that results in optic nerve atrophy, which usually causes permanent low visual acuity. Wallace et $a l^{1}$ reported a $\mathrm{G}$ to $\mathrm{A}$ mutation at nucleotide position (nt) 11778 of mitochondrial DNA (mtDNA) in nine of 11 LHON families. This mutation is usually homoplasmic. Although one half of Caucasian LHON pedigrees carry this mutation and some of the remaining pedigrees have putative LHON specific mutations (ex nt 3460 mutation, nt 4160 mutation), ${ }^{2-4}$ about $90 \%$ of Japanese LHON pedigrees have the nt 11778 mutation. ${ }^{5}$ We report an atypical LHON case with nt 11778 mutation. The first symptoms of diminished right visual acuity recovered and remained good, while the left visual acuity decreased and remained poor.

\section{Case report}

A 32-year-old man complained of right visual loss in February 1990. He was referred in April 1990 after no improvement with medications including corticosteroid at an ophthalmic clinic.
His corrected visual acuities were 20/200 right eye and 20/20 left eye. Automated static perimetry examination showed that the visual field impairment was due to a right co-central scotoma. The temporal aspect of the right optic disc was pale and the left optic disc was slightly reddened. The typical fluorescein angiography findings, including telangiectatic microangiopathy were not observed. Panel D-15 test showed colour disturbance (the axis was not clear) in his left eye. Bilateral elongations of the implicit time were detected in flash visually evoked potential (VEP) and pattern VEP. No remarkable finding was observed in the electroretinogram, electrocardiogram, or neurological examination, including cerebrospinal fluid examination and computed tomography scan. He was followed up at the ophthalmic clinic after no visual improvement with medications including corticosteroid as shown in Figure 1. Vitamins, coenzyme $\mathrm{Q}_{10}$, and ATP were also prescribed. We performed a molecular biological study using peripheral leucocytes for the patient, his father, and his mother (Fig 2). Informed consent was obtained from them. His mother has no clinical 


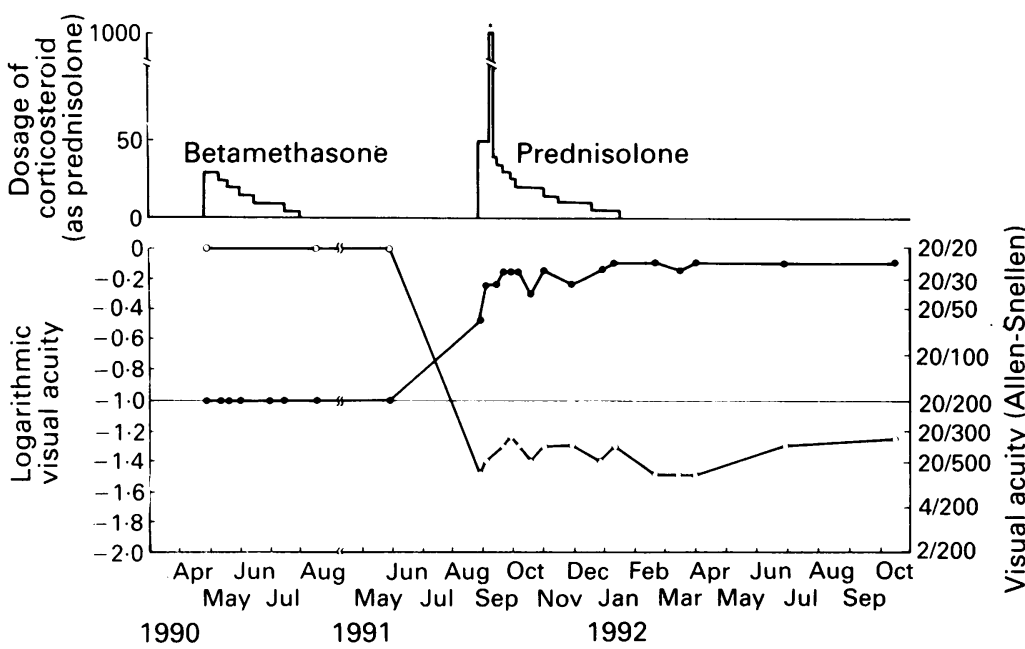

Figure 1 A time course of the visual acuity (right eye;, , left eye; $\bigcirc$ ) and corticosteroid therapy. Dosage of corticosteroid is shown as the amount of prednisolone. Asterisk shows the pulse therapy of hydrocortisone.

complaint except a minor colour disturbance in the 100-hue test (the axis was not clear). High molecular weight DNA including mtDNA was extracted from leucocytes. DNA fragments encompassing nt 11778 of mtDNA were amplified by polymerase chain reaction (PCR), digested by restriction enzymes Sfa NI and Mae
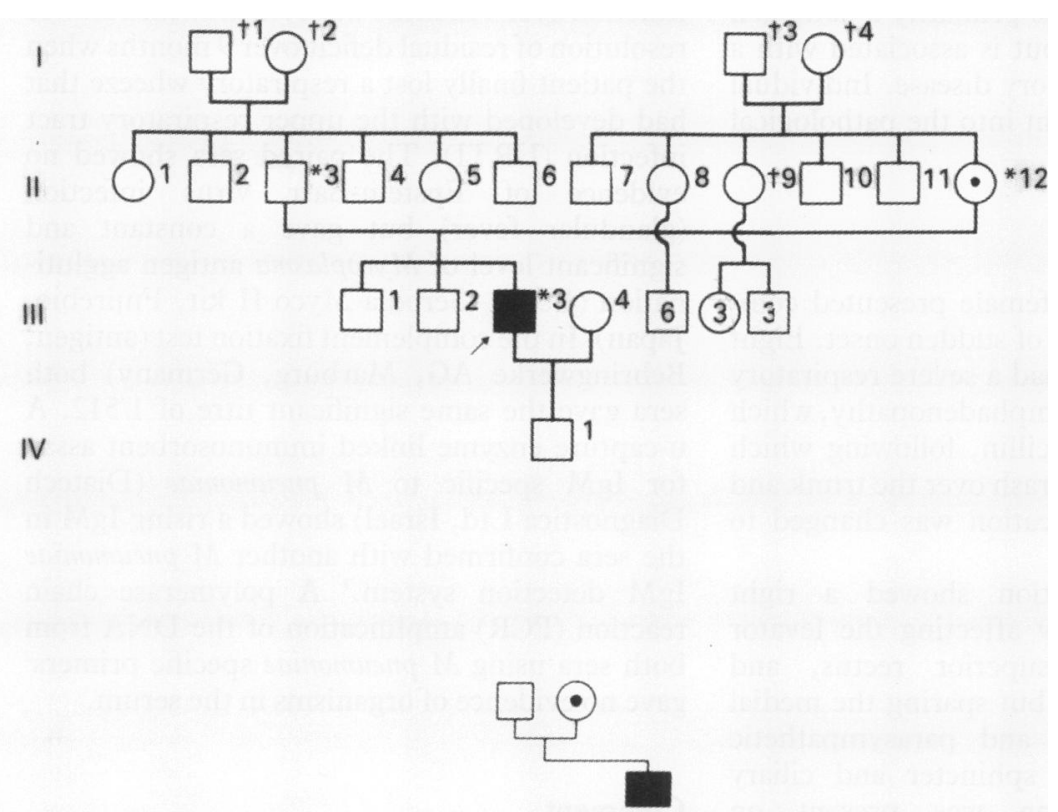

N II-3 II-12 III-3

Wild

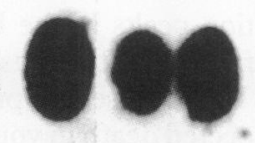

Mutant

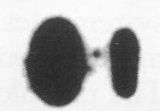
Figure 2 Top: Pedigree of family. (III-3) indicates an affected male and the proband.
Individuals examined clinically and by molecular biology are noted by an asterisk. Bottom: Slot Individuals examined clinically and by molecular biology are noted by an asterisk. Bottom: Slot
blot hybridisation of the wild type (upper row) and mutant (lower row) oligomers to polymerase chain reaction amplified DNA fragment. $N=$ normal control. Lanes II-3, II-12, III-3 correspond to the individuals shown at the top.
III and electrophoresed through a $2 \%$ agarose gel. Ten microlitres of the PCR reaction mixture were denatured, transferred to a nylon membrane, and fixed by ultraviolet light. The blots were hybridised with 5 -end labelled 21-mers of the wild (ACTCACAGTCGCATCATAATC) and the mutant (ACTCACAGTCACATCATAATC) oligonucleotides in $5 \times \mathrm{SSPE} / 5 \times$ Denhardt's solution $/ 0 \cdot 5 \%$ sodium dodecyl sulphate (SDS) for 2 hours at temperatures between $50^{\circ} \mathrm{C}$ and $60^{\circ} \mathrm{C}$, washed in $2 \times \mathrm{SSPE} / 0 \cdot 1 \% \mathrm{SDS}$ at $50^{\circ} \mathrm{C}$, and autoradiographed. Band intensities of the autoradiograph were quantified by densitometry. Restriction enzyme digestions revealed that the patient showed almost all mutant mtDNA pattern, the father showed all wild mtDNA pattern, and the mother showed half normal bands (data not shown). Slot blot hybridisation analysis demonstrated that the patient has almost all mutant mtDNA, the father has almost all wild mtDNA, and the mother has $48.9 \%$ wild and $51 \cdot 1 \%$ mutant mtDNA (heteroplasmy). Since we obtained the molecular biological data, we recommended that the patient have genetic counselling. We described the poor visual prognosis of LHON with the 11778 mutation. ${ }^{6}$ Although no remarkable change was observed in May 1991, his left visual acuity decreased with recovery of right visual acuity in July 1991. No remarkable change was observed with medications including hydrocortisone pulse therapy. His corrected visual acuities now are 20/25 right eye and 20/400 left eye.

\section{Comment}

Although the pathogenesis of LHON is still unknown, several mutations associated with LHON have already been reported. Newman et $a^{6}{ }^{6}$ reported that visual acuity was $20 / 200$ or worse in 107 of $109(98.2 \%)$ eyes with 11778 LHON. Stone $e t a l^{7}$ reported that recovery of visual acuity was recognised in only five of the 136 (4\%) 11778 LHON. This statistical information suggests a poor prognosis for our case. During 2.5 years of follow up, the right visual acuity recovered and remained good, while the left visual acuity decreased and remained low. These changes seem to be the natural course of the disease because they occurred independently of the medications. Our case showed the possibility (although in a small percentage) of recovering the visual acuity in LHON with nt 11778 mutation unrelated to the medications.

His mother is clinically normal except for a minor colour disturbance in the 100-hue test. The molecular biological study showed that she is a carrier. The reasons why the mother, with $50 \%$ mutant leucocyte mtDNA, does not have LHON are as follows: (1) $50 \%$ of the mtDNA is insufficient to trigger the disease; (2) distribution of the mutant mtDNA in the optic nerve is different from that in the leucocyte; (3) strong male bias suggests that $\mathrm{X}$ linked factors could contribute to the phenotypic expression. Although further study is required to clarify the pathogenesis of LHON, the nt 11778 mutation of mtDNA has a dose association with the cause of the LHON. 
1 Wallace DC, Singh G, Lott MT, Hodge JA, Shurr TG, Lezza AMS, et al. Mitochondrial DNA mutation associated with Leber's hereditary optic neuropathy. Science 1988; 242: 1427-30.

2 Howell N, Kubacka I, Xu M, McCullough DA. Leber hereditary optic neuropathy: involvement of the mitochondrial NDl gene and evidence for an intragenic suppressor mutation. Am $\mathcal{F}$ Hum Genet 1991; 48: $935-42$.

3 Huoponen K, Vilkki J, Aula P, Nikoskelainen EK, Savontaus $M-L$. A new mtDNA mutation associated with Leber hereditary optic neuroretinopathy. Am $\mathcal{f}$ Hum Genet 1991; 48: 1147-53.

4 Brown MD, Voljavec AS, Lott MT, Torroni A, Yang C-C, Wallace DC. Mitochondrial DNA complex I and III mutations associated with Leber's hereditary optic neuropathy. Genetics 1992; 130: 163-73.

Nakamura M, Ara F, Yamada M, Hotta Y, Hayakawa M, Fujiki $\mathrm{K}$, et al. A high frequency of mitochondrial ND4 gene mutation in Japanese pedigrees with Leber hereditary optic neuropathy. Jpn f Ophthalmol 1992; 36: 56-61.

6 Newman NJ, Lott MT, Wallace DC. The clinical characteristics of pedigrees of Leber's hereditary optic neuropathy with the 11778 mutation. Am 7 Ophthalmol 1991; 111: $750-62$.

7 Stone EM, Newman NJ, Millar NR, Johns DR, Lott MT, Wallace DC. Visual recovery in patients with Leber's hereditary optic neuropathy and the 11778 mutation. $\mathcal{f}$ Clin Neuro-ophthalmol 1992; 12: 10-4.

\title{
A cranial nerve palsy associated with Mycoplasma pneumoniae infection
}

\section{Polymerase chain reaction evidence against an infectious mechanism}

\author{
C G Fink, L Butler
}

John Radcliffe Hospital, Oxford

C G Fink

\section{Paybody Eye Unit,} Coventry and Warwickshire Hospital, Coventry CV1 4FH L Butler

Correspondence to: Dr Colin G Fink, Clinical Virology, Level 6, John Radcliffe Hospital, Headington, Oxford OX3 9DU.

Accepted for publication 15 June 1993
Mycoplasma pneumoniae is primarily a pathogen of the respiratory tract but is associated with a spectrum of non-respiratory disease. Individual cases provide some insight into the pathological processes.

\section{Case report}

A 4-year-old Caucasian female presented complaining of double vision of sudden onset. Eight days earlier the patient had a severe respiratory tract infection without lymphadenopathy, which was treated with amoxycillin, following which she developed a macular rash over the trunk and limbs for 5 days. Medication was changed to erythromycin.

Ophthalmic examination showed a right partial third nerve palsy affecting the levator palpebrae superioris, superior rectus, and inferior oblique muscle, but sparing the medial rectus, inferior rectus, and parasympathetic fibres to the pupillary sphincter and ciliary muscles. Double vision was present on attempted upgaze but absent in the primary position. Bell's phenomenon was equivocal on first visit and normal subsequently. The patient's visual acuity was $6 / 5$ unaided in both eyes. There was no evidence of intraocular pathology. Orbital or sinus pathology was excluded. A computed tomogram was normal and a lumbar puncture was not clinically justified.

The rash and chest infection resolved 8 days after first presentation. Blood was taken for an antibody screen with a follow up blood sample 10 days later.

There was no further progression of the third nerve palsy after presentation. A recovery of function over 4 months was evident with a slower resolution of residual deficit over 9 months when the patient finally lost a respiratory wheeze that had developed with the upper respiratory tract infection (URTI). The paired sera showed no evidence of Epstein-Barr virus infection (glandular fever) but gave a constant and significant level of Mycoplasma antigen agglutination (1/320) (Serodia-Myco-II kit, Fujirebio, Japan). In the complement fixation test (antigen; Behringwerke AG, Marburg, Germany) both sera gave the same significant titre of $1 / 512$. A u-capture enzyme linked immunosorbent assay for IgM specific to $M$ pneumoniae (Diatech Diagnostica Ltd, Israel) showed a rising IgM in the sera confirmed with another $M$ pneumoniae IgM detection system.' A polymerase chain reaction (PCR) amplification of the DNA from both sera using $M$ pneumoniae specific primers ${ }^{2}$ gave no evidence of organisms in the serum.

\section{Comment}

$M$ pneumoniae infection causes intermittent infection in the community between 4 year infection peaks in the United Kingdom. In the respiratory tract it causes illnesses ranging from mild URTI to severe pneumonia and occasional unexpected death in young people. ${ }^{345}$ It has been recorded as the cause of non-respiratory disease in children and adults including central nervous system lesions, haemolytic anaemia ${ }^{6}$ and maculopapular rash or erythema multiforme. The pathological processes in Mycoplasma nonrespiratory manifestations are believed to involve an exaggerated immune response possibly with induction of autoantibodies, changes of the proteins on the red cell 